\title{
PERAN KELOMPOK TANI TERHADAP PENDAPATAN PETANI PADI SAWAH DI KELURAHAN KAUMAN KIDUL KECAMATAN SIDOREJO KOTA SALATIGA
}

\author{
Lolita Geofanny Pramono dan Yuliawati \\ Program Studi Agribisnis Fakultas Pertanian dan Bisnis \\ Universitas Kristen Satya Wacana \\ Jl. Diponegoro 52-60, Salatiga 50711 \\ yuliawati.fpb@uksw.edu
}

\begin{abstract}
Farmers' group role is a set of farmers' behavior which self-connected in supplying farming production facility, cooperating with internal and external group, and also developing business unit together, thus will affect the income. This research aimed to understand the roles of farmers' group against the income of rice farmer in Kauman Kidul. Farmer's group role was measured from 4 independent variable, consist of study class role, cooperation role, production facility provider role and information-technology assembler role. The sampling method used in this research was proportional random sampling, constitute of 67 farmers as research respondents. Data was retrieved within interview process by mean of questionnaire. Data analysis technique has been done using multiple linear regression, processed with SPSS, ]. 25. Result showed that farmer's group role as a study class, a cooperation, and a production unit provider significantly affect the farmers' income, but farmers' group role as an information-technology provider doesn't affect income of rice farmer in Kauman Kidul, Sidorejo Subdistrict, Salatiga City.
\end{abstract}

Keywords: Farmers' group role, farmers' income, rice

\section{PENDAHULUAN}

Padi sebagai komoditas pangan utama mempunyai nilai strategis tinggi, sehingga diperlukan suatu penanganan dalam upaya peningkatannya. Upaya penanganan tersebut tidak lepas dari peran pemerintah dalam menyediakan bantuan bagi petani. Salah satu cara pemerintah membantu perkembangan pertanian adalah melakukan pembentukan kelembagaan atau kelompok sosial di dalam kehidupan masyarakat petani. Peran kelembagaan pertanian bagi petani antara lain: menyediakan fasilitas yang dibutuhkan oleh petani (sarana produksi), meningkatkan posisi tawar menawar petani dalam kegiatan ekonomi, sehingga dapat mengurangi kesenjangan dan kerugian yang dialami oleh petani (Pradana, 2013). Kelembagaan yang terdapat dalam usahatani produksi disebut sebagai kelompok tani dan rumah tangga petani dianggap sebagai unit terkecil.

Kelompok tani adalah sekumpulan petani yang dibentuk atas dasar kesamaan kepentingan yang berada dalam kondisi lingkungan (sosial, ekonomi, sumber daya) ditambah dengan keakraban antar petani memajukan usahatani anggota. Pembinaan kelompok tani ditujukan pada pengaplikasian sistem agribisnis dan peningkatan peran serta petani dengan cara berkerjasama antar petani 
dan pihak lain yang terkait untuk mengembangkan usahatani petani. Selain itu kegiatan pembinaan ini diharapkan dapat memberikan manfaat bagi petani diantaranya adalah membantu mengeksplorasi potensi yang dimiliki petani sehingga petani dapat secara mandiri mengatasi persoalan yang ada di usahataninya, serta mempermudah petani untuk mencari informasi perkembangan pasar, teknologi, permodalan, dan lain - lain sehingga dapat meningkatkan produktivitas dan pendapatan anggota kelompok tani.

Kecamatan Sidorejo merupakan wilayah sentra padi sawah di Kota Salatiga yang memiliki jumlah kelompok tani relatif stabil dibandingkan dengan wilayah lainnya. Pembentukan kelompok tani di wilayah tersebut bertujuan untuk meningkatkan dan mengembangkan kemampuan petani agar lebih berperan dalam pembangunan. Beberapa hasil kajian empiris menunjukkan bahwa berperannya suatu kelompok tani akan mendukung kelompok dan anggota kelompok tani tersebut dalam menjalankan usahatani masing - masing yang berpengaruh pada kondisi pendapatan anggota kelompok tani (Prasetia, 2011 dan Ikbal, 2014), sedangkan Irawati (2015) menyatakan bahwa dengan adanya kelompok tani maka dapat memudahkan dan membantu anggota kelompok tani untuk menjalankan kegiatan usahataninya. Kemudahan tersebut yaitu tersalurnya bantuan dari pemerintah melalui kelompok tani kepada petani - petani penerima bantuan dan berbagi pengalaman tentang usahatani. Hal itulah yang kemudian dimanfaatkan oleh petani untuk bergabung menjadi anggota kelompok tani agar meningkatkan pendapatannya..

Berdasarkan uraian di atas, penelitian ini bertujuan untuk mengetahui peran kelompok tani terhadap pendapatan petani padi sawah di Kelurahan Kauman Kidul, Kecamatan Sidorejo, Kota Salatiga. Peran kelompok diukur dari empat variabel independen yaitu peran sebagai kelas belajar, peran dalam kerjasama, peran sebagai penyedia unit produksi, peran dalam penerapan teknologi dan informasi.

\section{METODE PENELITIAN}

Penelitian dilaksanakan pada bulan Maret sampai dengan April 2019. Lokasi penelitian di Kelurahan Kauman Kidul, Kecamatan Sidorejo, Kota Salatiga - Jawa Tengah. Pemilihan lokasi penelitian dilakukan secara sengaja (purposive) dengan pertimbangan Kecamatan Sidorejo merupakan sentra penghasil padi dengan luas lahan sawah terbesar di Kota Salatiga dan Kelurahan Kauman Kidul memiliki jumlah kelompok tani dan anggota tani terbanyak dari seluruh kelurahan yang ada di Kecamatan Sidorejo.

Populasi penelitian ini adalah seluruh anggota dari lima kelompok tani di Kelurahan Kauman Kidul, Kecamatan Sidorejo, Kota Salatiga sejumlah 204 orang. Penentuan jumlah sampel menggunakan rumus Slovin 
Tabel 1. Penentuan Jumlah Sampel per Kelompok Tani

\begin{tabular}{llcl}
\hline No & Nama Kelompok Tani & $\begin{array}{c}\text { Jumlah Anggota } \\
\text { (orang) }\end{array}$ & Sampel (orang) \\
\hline 1 & Ringin Agung & 45 & 15 \\
2 & Ngudi Raharjo & 49 & 16 \\
3 & Ngudi Lestari & 34 & 11 \\
4 & Sumber Rejeki & 37 & 12 \\
5 & Maju Makmur & 39 & 13 \\
\hline Jumlah & & 204 & 67 \\
\hline
\end{tabular}

Sumber: Dinas Pertanian,2017 diolah

dengan standar error $10 \%$ sehingga jumlah responden yang ditetapkan sebesar 67 orang. Teknik pengambilan sampel secara proportional random sampling (Tabel 1).

Data yang digunakan dalam penelitian ini adalah data primer dan sekunder. Data primer diperoleh dari hasil wawancara menggunakan instrumen penelitian berupa kuisioner yang telah diuji validitas dan reliabilitasnya. Data sekunder diperoleh dari studi pustaka dan instansi terkait penelitian. Variabel bebas yang digunakan dan dianalisis dalam penelitian ini adalah peran kelompok tani sebagai kelas belajar $\left(\mathrm{X}_{1}\right)$, peran kelompok tani dalam kerjasama $\left(\mathrm{X}_{2}\right)$, peran kelompok tani sebagai penyedia input dan unit produksi $\left(\mathrm{X}_{3}\right)$, peran kelompok tani dalam penerapan teknologi dan informasi $\left(\mathrm{X}_{4}\right)$. Pengukuran variabel bebas menggunakan skala Likert 1-5. Variabel terikat dalam penelitian ini adalah pendapatan (Y). Penelitian ini pada dasarnya menggunakan data ordinal sebagai variabel bebas $(\mathrm{X})$ dan data rasio sebagai variabel terikat (Y) dengan model yang digunakan yaitu regresi linier berganda. Sebelum dilakukan analisis regresi linier berganda, data ordinal tersebut terlebih dahulu diubah menjadi data interval dengan menggunakan Method of Successive Interval (MSI) sedangkan untuk menghilangkan keragaman variabel $\mathrm{Y}$ atau pendapatan yang ditimbulkan oleh luas lahan, data rasio yang digunakan adalah pendapatan per hektar. Penelitian serupa pernah dilakukan oleh Nugraha (2013), Irawati (2015), dan Wardani (2019).

Peran kelompok tani terhadap pendapatan dianalisis dengan regresi linear berganda menggunakan software EViews 8 dengan model persamaan sebagai berikut:

$$
Y=\beta_{0}+\beta_{1} X_{1}+\beta_{2} X_{2}+\beta_{3} X_{3}+\beta_{4} X_{4}+
$$

$\mathrm{e}$

Keterangan :

$\mathrm{Y}=$ pendapatan

$\mathrm{X}_{1}=$ peran kelompok tani sebagai kelas belajar

$\mathrm{X}_{2}=$ peran kelompok tani dalam kerjasama

$\mathrm{X}_{3}=$ peran kelompok tani sebagai penyedia input dan unit produksi

$\mathrm{X}_{4}=$ peran kelompok tani dalam penerapan teknologi dan informasi

$$
\text { e }=\text { error }
$$


Tabel 2. Karakeristik Petani

\begin{tabular}{lcc}
\hline \multicolumn{1}{c}{ Karakteristik } & \multicolumn{2}{c}{ Petani Padi Sawah } \\
Responden & Jumlah orang & Presenase (\%) \\
\hline Umur (Tahun) & 20 & 29,8 \\
$40-52$ & 33 & 49,3 \\
$53-64$ & 14 & 20,9 \\
$65-76$ & 67 & 100 \\
\hline Jumlah & & \\
\hline Tingkat Pendidikan & 46 & 68,7 \\
SD & 13 & 19,4 \\
SMP & 8 & 11,9 \\
SMA & 67 & 100 \\
\hline Jumlah & & \\
\hline Luas Lahan & 28 & 41,8 \\
$900-2.200$ & 31 & 46,3 \\
2.300 - 3.500 & 8 & 11,9 \\
3.600 - 5.000 & 67 & 100 \\
\hline Jumlah & &
\end{tabular}

\section{HASIL DAN PEMBAHASAN}

\section{Karakteristik Petani Anggota Kelompok}

\section{Tani Kelurahan Kauman Kidul}

Berdasarkan hasil penelitian, usia petani di Kelurahan Kauman Kidul sangat bervariasi yaitu berkisar 40 - 74 tahun. Umur produktif yaitu berkisar 15 - 64 tahun, sehingga sebanyak 53 orang petani kelompok tani berada pada usia produktif dan cukup potensial untuk melakukan kegiatan usahatani. Menurut Sriyoto (2016) petani yang berada pada usia produktif diharapkan berpengaruh terhadap produktivitas kemampuan bekerjanya dan meningkatkan produksi. Tingkat pendidikan seseorang akan mempengaruhi kemampuan seseorang untuk menerima inovasi baru, serta berpengaruh dalam melakukan kegiatan usahatani. Berdasarkan tabel diatas tingkat pendidikan yang paling banyak dimiliki oleh petani adalah tamat sekolah dasar (SD) sebanyak 46 orang $(68,7 \%)$. Luas lahan petani anggota kelompok tani padi sawah bervariasi antara $900 \mathrm{~m}^{2}$ hingga $5.000 \mathrm{~m}^{2}$ dengan jumlah responden petani terbesar adalah pada luas interval $2.300-3.500 \mathrm{~m}^{2}$ sebanyak 31 orang dengan presentase $46,3 \%$.

\section{Peran Kelompok Tani Terhadap}

\section{Pendapatan}

Hasil analisis peranan kelompok tani terhadap pendapatan ditampilkan pada Tabel 2 
Tabel 2. Peran Kelompok Tani terhadap Pendapatan

\begin{tabular}{lcccl}
\hline \multicolumn{1}{c}{ Variabel } & $\begin{array}{c}\text { Coefficien } \\
\boldsymbol{t}(\mathbf{B})\end{array}$ & $\begin{array}{c}\text { Std. } \\
\text { Error }\end{array}$ & $\begin{array}{c}\boldsymbol{t} \text { - } \\
\text { Statistic }\end{array}$ & \multicolumn{1}{c}{ Probability } \\
\hline $\mathrm{c}$ & 2,352 & 2,688 & 0,875 & 0,385 \\
$\mathrm{X}_{1}$ & 0,682 & 0,305 & 2,234 & $0,029^{*}$ \\
$\mathrm{X}_{2}$ & 0,460 & 0,190 & 2,429 & $0,018^{*}$ \\
$\mathrm{X}_{3}$ & 0,447 & 0,239 & 1,872 & $0,066^{* *}$ \\
$\mathrm{X}_{4}$ & $-0,160$ & 0,333 & $-0,481$ & $0,632 \mathrm{ts}$ \\
$R$-squared & 0,522 & $\mathrm{t}$-tabel & $1,294^{*}$ & \\
Adjusted $R$ - & & $\mathrm{t}$-tabel & $1,668^{* *}$ & \\
squared & 0,491 & & \\
S.E. of regression & 3,862 & F-tabel & 2,52 & \\
F-statistic & 16,912 & & & \\
\hline
\end{tabular}

Sumber: Analisis Data Primer yang Diolah, 2019

*Signifikan pada $\alpha: 0,10(10 \%)$; **Signifikan pada $\alpha: 0,05(5 \%)$; ts: tidak signifikan

Berdasarkan tabel di atas, maka dapat disusun persamaan regresi linier berganda peranan kelompok tani terhadap pendapatan sebagai berikut:

$$
Y=2,352+0,682 X_{1}+0,460 X_{2}+0,447
$$

$\mathrm{X}_{3}-0,160 \mathrm{X}_{4}+2,688$

Uji ketepatan model peran kelompok tani terhadap pendapatan berdasarkan nilai koefisien determinasi $\left(\mathrm{R}^{2}\right)$ sebesar 0,522 menunjukkan 52,2\% variasi pendapatan dapat dijelaskan oleh variasi peran kelompok tani sebagai kelas belajar $\left(\mathrm{X}_{1}\right)$, peran kelompok tani dalam kerjasama $\left(\mathrm{X}_{2}\right)$, peran kelompok tani sebagai penyedia input dan unit produksi $\left(\mathrm{X}_{3}\right)$ dan peran kelompok tani dalam penerapan teknologi dan informasi $\left(\mathrm{X}_{4}\right)$ sedangkan sisanya $(47,8 \%)$ dijelaskan oleh faktor lain di luar model. Nilai $F_{\text {hitung }}$ sebesar 16,912 lebih besar dari $\mathrm{F}_{\text {tabel }} 2,52$ pada tingkat kesalahan 5\% $(\alpha=0,05)$, berarti peran kelompok tani sebagai kelas belajar $\left(\mathrm{X}_{1}\right)$, peran kelompok tani dalam kerjasama $\left(\mathrm{X}_{2}\right)$, peran kelompok tani sebagai penyedia unit produksi $\left(\mathrm{X}_{3}\right)$ dan peran kelompok tani dalam penerapan teknologi dan informasi $\left(\mathrm{X}_{4}\right)$ secara bersama-sama berpengaruh terhadap pendapatan (Y).

Peran Kelompok Tani sebagai Kelas Belajar terhadap Pendapatan

Dari hasil Tabel 2 dapat dilihat peran kelompok tani sebagai kelas belajar berpengaruh positif dan signifikan terhadap pendapatan, ditunjukkan dari nilai thitung 2,234 $>\mathrm{t}_{\text {tabel }} 1,668$ pada tingkat kepercayaan $95 \%$ atau nilai probabilitasnya $0,029 * *$ lebih rendah dari nilai signifikan yang telah ditentukan yaitu 0,05. Nilai koefisien regresi peran kelompok tani sebagai kelas belajar sebesar 0,682 menunjukkan setiap peningkatan satu satuan peran kelompok tani sebagai kelas belajar akan meningkatkan pendapatan sebesar Rp 680.000. 
Tabel 3. Sebaran Skor Kelas Belajar dan Rerata Pendapatan

\begin{tabular}{ccccc}
\hline Skor & $\begin{array}{c}\text { Rerata Pendapatan } \\
(\mathrm{Rp} / \mathrm{ha})\end{array}$ & $\begin{array}{c}\text { Jumlah } \\
\text { Responden }\end{array}$ & $\begin{array}{c}\text { Persentase } \\
(\%)\end{array}$ & Keterangan \\
\hline $5-12$ & 3.605 .000 & 1 & 1,5 & Kurang Baik \\
$13-20$ & 5.809 .584 & 51 & 76,1 & Cukup \\
$21-28$ & 5.477 .133 & 15 & 22,4 & Baik \\
\hline & Jumlah & 67 & 100,00 & \\
\hline
\end{tabular}

Berdasarkan tabel diatas variabel penelitian Irawati (2015) yang menyatakan kelompok tani sebagai kelas belajar di kelompok tani Kelurahan Kauman Kidul termasuk dalam kategori cukup baik pada interval skor 13 - 20 sebanyak 51 responden $(76,1 \%)$ dengan rerata pendapatan sebesar Rp 5.809.584, hal ini juga dapat diartikan bahwa kelas belajar mempengaruhi pendapatan petani. Kelas belajar yaitu tempat bagi anggota kelompok tani meningkatkan pengetahuan dan keterampilan mengenai usahatani. Berdasarkan keadaaan dilapangan fungsi kelompok tani sebagai kelas belajar dibuktikan dengan berbagi pengalaman serta terlibatnya anggota dalam menentukan materi pembelajaran, dimana materi itu akan digunakan untuk penyuluhan serta pelatihan kepada petani. Hal ini sesuai dengan bahwa dengan adanya kelompok tani, petani anggota dapat berinteraksi baik berbagi pengalaman ataupun menyelesaikan persoalan tentang usahatani secara musyawarah.

\section{Peran Kelompok Tani dalam Kerja sama terhadap Pendapatan}

Berdasarkan Tabel 2 dapat dilihat peran kelompok tani dalam kerjasama $\left(\mathrm{X}_{2}\right)$ bertanda positif dan signifikan terhadap pendapatan, ditunjukkan dari nilai $t_{\text {hitung }} 2,429>\mathrm{t}_{\text {tabel }} 1,668$ pada tingkat kepercayaan 95\%. Atau nilai probabilitasnya sebesar 0,018 lebih rendah dari nilai signifikan yang telah ditentukan yaitu 0,05. Nilai koefisien regresi peran kelompok tani dalam kerja sama $\left(\mathrm{X}_{2}\right)$ sebesar 0,460 menunjukkan setiap peningkatan peran kelompok tani dalam kerja sama akan

Tabel 4. Sebaran Skor Peran Kelompok Tani dalam Kerjasama dan Rerata Pendapatan

\begin{tabular}{ccccc}
\hline Skor & $\begin{array}{c}\text { Rerata } \\
\text { pendapatan (Rp/ha) }\end{array}$ & $\begin{array}{c}\text { Jumlah } \\
\text { Responden }\end{array}$ & Persentase (\%) & Keterangan \\
\hline $5-12$ & 5.988 .750 & 10 & 14,93 & Kurang Baik \\
$13-$ & 5.632 .261 & 49 & 53,73 & Cukup \\
20 & 5.772 .813 & 21 & 31,34 & Baik \\
$21-$ & 67 & 67 & 100,00 & \\
28 & Jumlah &
\end{tabular}


Tabel 5. Sebaran Skor Peran Kelompok Tani sebagai Penyedia Unit Produksi dan Rerata Pendapatan

\begin{tabular}{ccccc}
\hline Skor & $\begin{array}{c}\text { Rerata Pendapatan } \\
(\mathrm{Rp} / \mathrm{ha})\end{array}$ & $\begin{array}{c}\text { Jumlah } \\
\text { Responden }\end{array}$ & $\begin{array}{c}\text { Persentase } \\
(\%)\end{array}$ & Keterangan \\
\hline $5-12$ & 3.605 .000 & 1 & 1,49 & Kurang Baik \\
$13-$ & 5.832 .974 & 46 & 68,7 & Cukup \\
20 & 5.506 .450 & 20 & 29,9 & Baik \\
$21-28$ & Jumlah & 67 & 100 & \\
\hline
\end{tabular}

mengakibatkan peningkatan pendapatan sebesar Rp 460.000.

Berdasarkan tabel diatas variabel kelompok tani sebagai kerjasama di kelompok tani Kelurahan Kauman Kidul termasuk dalam kategori cukup baik pada interval skor 13 - 20 sebanyak 49 responden $(53,73 \%)$ dengan rerata pendapatan sebesar $\mathrm{Rp}$ 5.632.261, hal ini juga dapat diartikan bahwa kerjasama mempengaruhi pendapatan petani. Hal ini sesuai dengan hasil penelitian Siregar (2018) yang menyatakan bahwa kelompok tani berperan dalam sebagai wahana kerjasama antar petani dan pemberi kelas belajar. Semua anggota kelompok tani melakukan pelatian dengan kelompok tani lainnya yang tergabung dalam Gapoktan yaitu Prima Agung dengan bantuan penyuluh pertanian serta kelompok tani bekerjasama dengan penyedia jasa pertanian yaitu pengolah hasil panen atau disebut penggiling padi di Kelurahan Kauman Kidul.

\section{Peran Kelompok Tani sebagai Penyedia}

\section{Unit Produksi terhadap Pendapatan}

Berdasarkan Tabel 2 dapat dilihat peran kelompok tani sebagai penyedia unit produksi $\left(\mathrm{X}_{3}\right)$ bertanda positif dan signifikan terhadap pendapatan, ditunjukkan dari nilai thitung 1,872 $>\mathrm{t}_{\text {tabel }} 1,294^{*}$ pada tingkat kepercayaan $90 \%$ atau nilai probabilitasnya sebesar 0,066 lebih rendah dari nilai signifikan yang telah ditentukan yaitu $0,10^{*}$. Nilai koefisien regresi peran kelompok tani sebagai penyedia unit produksi $\left(\mathrm{X}_{3}\right)$ sebesar 0,447 menunjukkan setiap peningkatan peran kelompok tani sebagai penyedia unit produksi akan meningkatkan pendapatan sebesar Rp 447.000 .

Berdasarkan tabel diatas variabel kelompok tani sebagai penyedia unit produksi di kelompok tani Kelurahan Kauman Kidul termasuk dalam kategori cukup baik pada interval skor 13 - 20 sebanyak 46 responden $(68,7 \%)$ dengan rerata pendapatan sebesar $\mathrm{Rp}$ 5.832.974. Peran kelompok tani sebagai unit produksi adalah dengan meyediakan sarana dan prasana penunjang usahatani anggotanya. Berdasarkan keadaan dilapangan anggota 
kelompok tani memberikan bantuan kepada anggota berupa benih, pupuk dan pestisida yang selalu diberikan pada saat awal musim tanam padi sehingga petani dapat menggunakan input tersebut untuk memulai kerja dilahan masing - masing. kelima kelompok tani tergabung dalam gabungan kelompok tani (Gapoktan) yaitu Prima Agung juga menyediakan bantuan pengolahan padi menjadi beras dengan adanya mesin penggiling serta bantuan akses pasar yang mempermudah petani menjual hasil yaitu dijual di Gapoktan Prima Agung dengan harga yang relatif stabil dari harga pasaran yang berlaku saat itu.

\section{Peran Kelompok Tani dalam Penerapan}

\section{Teknologi dan Informasi terhadap}

\section{Pendapatan}

Berdasarkan Tabel 2 dapat dilihat peran kelompok tani dalam penerapan teknologi dan informasi $\left(\mathrm{X}_{4}\right) \quad$ tidak signifikan mempengaruhi pendapatan, ditunjukkan dari nilai thitung $-0,481>\mathrm{t}_{\text {tabel }} 1,668$ pada tingkat kepercayaan 95\%. Atau nilai probabilitasnya sebesar 0,632 lebih besar dari nilai signifikan yang telah ditentukan yaitu 0,05. Nilai koefisien regresi peran kelompok tani dalam penerapan teknologi dan informasi $\left(\mathrm{X}_{4}\right)$ sebesar -0,160. Rendahnya signifikansi dari nilai $\mathrm{X}_{4}$ yaitu penerapan teknologi dan informasi identik dengan hasil penelitian Wardani (2019). Dalam penelitiannya tersebut, pemanfaatan teknologi dalam bentuk penggunaan bibit unggul tidak memberikan pengaruh secara signifikan terhadap pendapatan petani karena kurang optimal. Pemanfaatan teknologi tergantung dari respon dan kemauan petani dalam menerapkan teknologi tersebut. Pendapat yang sama juga dikemukakan oleh Nuryanti \& Swastika (2011) bahwa efektivitas kelompok tani dalam membangun pertanian dalam konteks teknologi sangat berkaitan dengan sumber daya manusia yaitu petani itu sendiri. Antusiasme dan keterampilan petani sangat dibutuhkan untuk menerapkan teknologi yang disediakan oleh pemerintah melalui kelompok tani. Jadi efektivitas pemanfaatan teknologi tidak semata-mata dipengaruhi oleh kelompok tani tetapi juga membutuhkan peran dari petani secara langsung

Berdasarkan tabel diatas variabel kelompok tani sebagai penyedia unit produksi

Tabel 6. Sebaran Skor Peran Kelompok Tani dalam Penerapan Teknologi dan Informasi dan Rerata Pendapatan

\begin{tabular}{ccccc}
\hline Skor & $\begin{array}{c}\text { Rerata Pendapatan } \\
(\mathrm{Rp} / \mathrm{ha})\end{array}$ & $\begin{array}{c}\text { Jumlah } \\
\text { Responden }\end{array}$ & Persentase $(\%)$ & Keterangan \\
\hline $5-12$ & 7.008 .300 & 5 & 7,50 & Kurang Baik \\
$13-20$ & 5.619 .812 & 49 & 73,13 & Cukup \\
$21-28$ & 5.510 .654 & 13 & 19,4 & Baik \\
\hline & Jumlah & 67 & 100 & \\
\hline
\end{tabular}


di kelompok tani Kelurahan Kauman Kidul termasuk dalam kategori cukup baik pada interval skor 13 - 20 sebanyak 49 responden $(73,13 \%)$ dengan rerata pendapatan sebesar Rp 5.619.812. Berdasarkan hasil wawancara dengan petani dan pengamatan selama penelitian, petani-petani yang tergabung dalam kelompok tani sudah cukup dalam kerjasama. Meskipun demikian, ada kendala yang cukup besar dalam hal adopsi teknologi penananm yaitu untuk kasus waktu tanam. Dalam hal waktu tanam, ada beberapa petani yang tidak mengikuti proses tanam serempak sehingga mengakibatkan serangan hama berupa tikus. Sistem tanam serempak diketahui dapat menghambat serangan tikus karena memutus rantai makanannya (Badan Litbang Pertanian, 2011).

Hal ini menunjukkan penerapan teknologi tidak diiringi dengan penguatan kerjasama antar kelompok tani, sehingga bertolak belakang pendapat Yani (2010) dimana jika peran kelompok sebagai kerjasama semakin tinggi, maka kemampuan anggota dalam penerapan teknologi dan informasi budidaya akan semakin baik. Berdasarkan penelitian yang dilakukan oleh Harisman (2014), diperlukan kerjasama antar petani untuk dapat memperlancar penerapan teknologi pola tanam SRI dalam satu lingkup kelompok petani.

\section{KESIMPULAN DAN SARAN}

\section{Kesimpulan}

1. Berdasarkan hasil penelitian peran kelompok tani dapat dikatakan pada kategori cukup baik dimana kelas belajar, kerjasama, penyedia unit produksi dan penerapan teknologi dan informasi dalam katerogi cukup baik.

2. Variabel kelas kelas belajar, kerjasama dan penyedia unit produksi memiliki berpengaruh yang signifikan terhadap pendapatan. Sedangkan variabel penerapan teknologi dan informasi tidak memiliki pengaruh yang signifikan terhadap pendapatan kelompok tani di Kelurahan Kauman Kidul, Kecamatan Sidorejo, Kota Salatiga.

\section{Saran}

Bagi petani diharapkan kesediaannya mengikuti tanam serempak sesuai dengan anjuran penyuluh pertanian setempat dan ketua kelompok tani masing - masing.

\section{DAFTAR PUSTAKA}

Badan Litbang Pertanian, 2011. Pengendalia Hama Toikus Terpadu. Sinartani. Edisi 17-23 Agustus. No. 3419. Tahun XLI. 5 hlm.

Badan Pusat Statistik (BPS). 2019. Luas Panen dan Produksi Padi dan Palawija Tahun 2014. https://salatigakota.bps.go.id/statictable/2 016/03/21/36/luas-panen-dan-produksipadi-dan-palawija-2014.html. Diakses 17 Januari 2019 
Badan Pusat Statistik (BPS). 2019. Luas Panen, Produksi dan Produktivitas Padi Sawah dan Padi Ladang Menurut Kabupaten/Kota di Jawa Tengah Tahun 2014. https://jateng .bps.go.id/statictable/2015/09/28/1191/lu as-panen-produksi-dan-produk tivitaspadi-sawah-dan-padi-ladang -menurutkabupaten-kota-di-jawa te ngah-tahun2014.html. Diakses 17 Januari 2019

Dinas Pertanian. 2017. Katalog Kelembagaan Pelaku Utama dan Pelaku Usaha Kelompok Tani (POKTAN) dan Gabungan Kelompok Tani (GAPOKTAN) Kota Salatiga Tahun 2017.

Harisman, Kundang. 2014. Pengaruh kemampuan kerjasama kelompok tani terhadap penerapan teknologi System of Rice Intensification (SRI) di Kabupaten Sumedang. Jurnal Istek 8 (2): 217-228

Ikbal, Mohamad. 2014. Peranan Kelompok Tani Dalam Meningkatkan Pendapatan Petani Padi Sawah Di Desa Margamulya Kecamatan Bungku Barat Kabupaten Morowali. e-Jurnal Agrotekbis 2 (5): 505-509

Irawati, Eni. dan M.R. Yantu. 2015. Kinerja Kelompok Tani Dalam Menunjang Pendapatan Usahatani Padi Sawah Di Desa Sidera Kecamatan Sigi Biromaru Kebupaten Sigi. e-Jurnal Agrotekbis 3 (2): 206-211

Nugraha, Demy Sebastian dan Ismudjiati. 2013. Pengaruh dinamika kelompok tani terhadap pendapatan usaha tani padi sawah (Oryza Sativa L.) (Studi kasus di Desa Sletreng, Kecamatan Kapongan, Kabupaten Situbondo). Agribios. 11 (2): 51-70

Nuryanti, Sri dan Dewa.K.S.Swastika. 2011. Peran Kelompok Tani Dalam Penerapan Teknologi Pertanian. Forum Penelitian Agro Ekonomi. 29 (2): 115-128

Pradana, Adhi Putu Bagus Ida. 2013. Peran Kelembagaan Dalam Pengembangan Usataha Tani Sayuran Organik Di Kelompok Tani Trianggulasi, Desa Batur, Kecamatan Getasan Kabupaten Semarang. Skripsi. Universitas Kristen Satya Wacana. Salatiga.
Prasetia, R. dan Tubagus. H. 2015. Peranan Kelompok Tani Dalam Peningkatan Pendapatan Petani Kopi di Kelurahan Tugusari Kecamatan Sumberjaya Kabupaten Lampung Barat. Jurnal JIIA 3 (3): 301-207

Siregar, Ricky Ananda, Muhammad Jufri, Rahmanta Ginting. 2018. Pengaruh kelompok tani terhadap pendapatan usahatani padi sawah (Kasus: Kelompok Sri Wangi, Desa Wonosari, Kecamatan Tanjung Morawa, Kabupaten Deli Serdang). Journal on Social Economic of Agriculture and Agribusiness 9 (8): 1-17

Sriyoto dan Bambang Sumantri. 2016. Kajian Peningkatan Pendapatan Pengrajin Gula Kelapa Di Desa Purbosari Kecamatan Seluma Barat Kabupaten Seluma. AGRISEP 16 (1): 37-44.

Wardani, Dwi Febrianty Nabila dan Dwi Susilowati. 2019. Peran kelompok tani dalam meningkatkan produktivitas usahatani kentang di Desa Sumber Brantas Kecamatan Bumiaji Kota Batu. Seagri 7 (2): 1-9

Yani, Diarsi Eka, Ludivica ES, Rinda Noviyanti. 2010. Persepsi anggota terhadap peran kelompok tani dalam meningkatkan kemampuan penguasaan teknologi budidaya belimbing. Jurnal Matematika, Sains, dan Teknologi 11 (2): 133-145. 